Brit. J. industr. Med., 1961, 18, 260.

\title{
A CLINICAL STUDY OF ELECTRICAL ACCIDENTS
}

\author{
BY \\ W. R. LEE \\ From the Nuffield Department of Occupational Health, University of Manchester
}

(RECEIVED FOR PUBLICATION MAY 18, 1961)

The report of a clinical study of 104 electrical accidents which befell 85 men is divided into two parts.

Part I enumerates the different types of accidents as flash burn, Joule burn, arc eye, "held on" shock and "not held" shock, physical shock, and death. These are related to the different voltages involved ranging from 240/415 (medium) voltage to 33 kilovolts. There appeared to be no association between voltage and type of injury and no evidence to suggest that any of the voltages are free from hazard. There were 53 cases of flash burn, affecting mostly the face and extensor surface of the hands and arms. The 16 cases of arc eye caused no serious concern. Of the 15 Joule burns all except one occurred at medium voltages in "held on" accidents, the other being associated with an electric shock at 33 kilovolts. The majority of Joule burns affected the flexor surfaces.

Part II of the paper deals with the 43 cases of electric shock (passage of current through the body). Thirty of these cases were "held on" to the circuit by the current. It was found that the longer a victim was held on to the circuit the greater appeared to be his chances of developing heart and chest symptoms suggestive of impending asphyxia, and of losing consciousness. Although about half of these men were released by an external agency and others struggled off, a number suddenly became free from the circuit without, they claimed, losing consciousness. This is difficult to explain. Artificial respiration was administered in two cases, one of whom was "held on" and was being asphyxiated. The other case received flash burns only and did not in fact receive an electric shock.

\section{PART I: GENERAL REVIEW AND NON-SHOCK CASES}

Electrical accidents receive little attention in British medical literature. In fact, in the electricity supply industry they account for only $1 \%$ of the total number of accidents but they are the commonest cause of accidental death (Hughes and Corney, 1956). In factories, electrical accidents account for less than $0.5 \%$ of all accidents, but more than $5 \%$ of these electrical accidents prove fatal (Emerson, 1961). This paper reports a clinical investigation into a series of electrical accidents; detailed consideration of the cases of electric shock (passage of current through the body) is given in Part II of this paper.

\section{Method}

The names of all men in an electricity supply undertaking who had sustained an electrical accident during the preceding three years were obtained. Of the total of 114, 107 were still employed by the undertaking. One man was killed; the remainder were contacted and 84 attended for interview. (The majority of those who were not seen worked in one small area and there is no reason to suppose that the nature of their accidents was any different from the whole.) They were all seen by one investigator and were questioned about the electrical and physical circumstances of the accident, about symptoms, and about subsequent medical history. Parts of the body reported as injured in the accident were examined and in cases of electric shock a complete physical examination was carried out. In addition to the electrical accidents for which they were seen (referred to hereafter as "series cases"), these persons recounted a further 19 electrical accidents (referred to hereafter as "additional cases"). It must be acknowledged that whilst the 84 "series cases" represent a group of electrical accidents selected only in the sense of those attending, the 19 "additional cases" are biased in content as a result of the investigator's interest in a particular type of electrical accident. For this reason "series cases" are considered separately from "additional cases" when the incidence of injuries is discussed. 
TABLE 1

INCIDENCE OF INJURIES

\begin{tabular}{|c|c|c|c|c|c|c|c|c|}
\hline & Flash Burn & Joule Burn & Arc Eye & "Held On" & $\begin{array}{c}\text { Shock } \\
\text { "Not Held" }\end{array}$ & $\begin{array}{l}\text { Physical } \\
\text { Shock }\end{array}$ & Death & $\begin{array}{l}\text { No. of } \\
\text { Accidents* }\end{array}$ \\
\hline $\begin{array}{l}\text { Series cases } \\
\text { Additional cases }\end{array}$ & $\begin{array}{r}53 \\
1\end{array}$ & $\begin{array}{r}10 \\
5\end{array}$ & 16 & $\begin{array}{l}14 \\
16\end{array}$ & $\begin{array}{r}10 \\
3\end{array}$ & $\begin{array}{l}3 \\
1\end{array}$ & 1 & $\begin{array}{l}85 \\
19\end{array}$ \\
\hline Total & 54 & 15 & 16 & 30 & 13 & 4 & 1 & 104 \\
\hline
\end{tabular}

* Several subjects sustained more than one class of injury as the result of a single accident.

TABLE 2

VOLTAGE INVOLVED

\begin{tabular}{|c|c|c|c|c|c|c|}
\hline & Medium & $2 \cdot 2-2 \cdot 4 \mathrm{kV}$ & $6.6 \mathrm{kV}$ & $11 \mathrm{kV}$ & $33 \mathrm{kV}$ & Total \\
\hline $\begin{array}{l}\text { Series cases } \\
\text { Additional cases }\end{array}$ & $\begin{array}{l}69 \\
18\end{array}$ & $\underline{3}$ & $\underline{3}$ & $\begin{array}{l}7 \\
1\end{array}$ & $\underline{3}$ & $\begin{array}{l}85 \\
19\end{array}$ \\
\hline Total & 87 & 3 & 3 & 8 & 3 & 104 \\
\hline
\end{tabular}

TABLE 3

RELATIONSHIP BETWEEN INJURY AND VOLTAGE (SERIES CASES)

\begin{tabular}{|c|c|c|c|c|c|c|c|c|}
\hline Voltage & Flash Burn & Joule Burn & Arc Eye & "Held On" & $\begin{array}{l}\text { Shock } \\
\text { "Not Held" }\end{array}$ & $\begin{array}{l}\text { Physical } \\
\text { Shock }\end{array}$ & Death & $\begin{array}{c}\text { No. of } \\
\text { Accidents* }\end{array}$ \\
\hline $\begin{array}{l}\text { Medium } \\
2 \cdot 2-2 \cdot 4 \mathrm{kV} \\
6 \cdot 6 \mathrm{kV} \\
11 \mathrm{kV} \\
33 \mathrm{kV}\end{array}$ & $\begin{array}{r}43 \\
3 \\
2 \\
3 \\
2\end{array}$ & $\frac{8}{1}$ & $\frac{14}{1}$ & $\frac{13}{1}$ & $\frac{9}{1}$ & $\frac{1}{3}$ & $\begin{array}{l}\bar{z} \\
\frac{1}{1}\end{array}$ & $\begin{array}{r}69 \\
3 \\
3 \\
7 \\
3\end{array}$ \\
\hline Total & 53 & 10 & 16 & 14 & 11 & 4 & 1 & 85 \\
\hline
\end{tabular}

*Several subjects sustained more than one class of injury as the result of a single accident.

\section{Electrical Accidents}

Electricity can cause injury to the body in three ways. First, by the conversion of electrical energy into light energy, which may injure the eye. Second, by the conversion of electrical energy into heat energy. If this takes place outside the body the heat is usually associated with a short-lived flame causing a flash burn. Whereas if the conversion of electrical energy into heat takes place within the body most heat is evolved where the resistance is highest, in conformity with Joule's Law, usually where the electrodes are in contact. The resulting burn is frequently referred to as a Joule burn. Third, the passage of an electric current through the body produces other effects grouped under the term "electric shock". In this study, cases of electric shock have been divided into two groups according to whether or not the victim was "held on" to the circuit by the current. The cases of electric shock are considered in greater detail in Part II of this paper. Finally, as in any accident, effects might be produced which are not the results of any of the electro-pathological phenomena. These are grouped under the term "physical shock", and are considered with the cases of electric shock.
Table 1 shows the incidence of injuries in both the "series cases" and "additional cases". It will be seen that burns account for at least half of the injuries.

\section{Voltaze}

Electricity is usually received by the distribution undertakings at $33 \mathrm{kV}$ and transmitted through their networks at this voltage and at $11 \mathrm{kV}, 6.6 \mathrm{kV}$, and $2 \cdot 4 \mathrm{kV}$. Finally, the voltage is reduced to $415 / 230$ (the so-called medium voltage) for distribution to the majority of consumers. It can be seen from Table 2 that in the "series cases" accidents occurred at all these voltages. It is not possible to draw conclusions regarding the proportions of accidents at different voltages, for the number of man-hours exposed at these voltages is not known. Certainly it is seen that the medium voltages are not free from hazard. Emerson (1961) states that in Great Britain approximately two-thirds of the electrical fatalities occur at voltages below 250 .

The relationship between injury sustained and voltage involved, in the "series cases" only, is shown in Table 3. It is seen that there is no indication that 
any particular voltage is associated with certain types of injury and, more important, there is no evidence to suggest that any of the voltages are free from hazard. All but one of the 14 "held on" cases occurred at medium voltage; one occurred at 6,000 volts. Of the 16 "held on" accidents seen in the "additional cases" all occurred at medium voltage. Whilst it is accepted that the phenomenon of being "held on" to a circuit is dependent on the strength of a current rather than its voltage (Dalziel, Lagen, and Thurston, 1941), it is of interest to note that "held on" shocks are generally associated with medium voltages.

\section{Arc Eye}

The occurrence of this condition following the flash of a short-circuiting current was first described by Rivers (1894) and Roy (1897). Altogether 16 subjects described the typical symptoms of arc eye, appearing a few hours after a flash accident. Nearly all these people were exposed to a short-lived flash within one or two feet of the eyes; in fact in seven of them there was singeing of the eyelashes, eyebrows, or hair, or first degree burns of the face.

In one case the arc eye was accompanied by other more serious injuries (second degree burns of the hands) which occasioned considerable loss of time from work (this was the same accident in which the only death in the series occurred). Omitting this case the 15 other cases of arc eye lost only 22 days from work between them as a result of the accident. The longest period off work was seven days, whilst nine persons lost no time at all. No cases of the less common, but more lasting forms of eye injury, such as the retinal changes described by Minton (1949), were cncountered.

\section{Burns}

Flash Burns.-As had been stated, flash burns result from a flame of very short duration. It is therefore to be expected that the exposed parts of the body, namely the face and extensor surfaces of the hands and arms, would be affected most frequently. It was found that 28 flash burn accidents affected the face, 37 the extensor aspects of the arms and hands, and only 10 the flexor aspects; two were unspecified (the total of these exceeds the total number of flash burn accidents (54) as an accident frequently resulted in burns at more than one site).

The periods of time lost as a result of flash burn are shown in Table 4.

It will be seen that just over half the flash burn accidents reported resulted in no lost time and that 42 out of 54 of the cases were back at work in a month. Five cases (just less than $10 \%$ ) were off for more than three months, and three of these were off for six months or longer.

Case 6.-He sustained second degree burns on the backs of both hands and a first degree burn on the left side of the face when arcing occurred at 415 volts at a street pillar on which he was working. As a result of the accident the pillar was destroyed and the patient's suit burned although it did not catch fire. He was still off work when seen eight months later.

Case 7.-This man was working on a 33,000 volt line in a sub-station when there was an explosion killing his colleague. In addition to arc eye and severe second degree flash burns of the face and backs of hands he sustained Joule burns of both palms and a violent electric shock which threw him off. He was away from work for just over six months.

Case 51 A.-This electrician was screwing a metal plate into position. The plate became live at 230 volts and flashed across to the neutral conductor. He estimated that the arcing lasted about two minutes, until the metal ends had burned themselves away. He states that he was held on to the circuit and close to the burning (although his left hand was holding the live metal plate, his right hand held an insulated screwdriver and he wore dry substantial rubber boots). This accident was in the "additional cases" series and had occurred several years previously; it was not possible to check details from the safety officer, e.g. the efficiency of insulation of the screwdriver. He was off work for about three months.

Case 58.-This man was injured during a flashover explosion between two 11,000 volt lines. He sustained burns to the backs of the hands and the front of the face and neck, which resulted in his being off work for about three months.

Case 75.--A jointer was working in a sub-station when there was an explosion in a nearby 6,600 volt apparatus to his right. The flame burned the backs of both his hands, his face, and the front of his scalp. His trousers and overall collar caught fire and resulted in burns to the neck and legs. The complication of flame burning by ignition of clothing has been discussed by Tempest and Atkins (1958). As a result of this accident the man was away from work for about six months.

It will be seen that out of five flash burn accidents resulting in absences of six months or longer, three occurred at voltages greater than 6,000 . The other two occurred at medium voltage and in one of these the subject was apparently "held on" close to the burning.

\section{Joule Burns}

Voltage and duration of current.-A Joule burn is caused by the passage of electric current through the skin. The heating effect of a current is given by the formula: $\mathbf{I}^{2} \mathbf{R t}$ where $\mathbf{I}=$ current, $\mathbf{R}=$ resistance, $\mathrm{t}=$ time.

For a given resistance, medium voltages are associated with smaller currents than higher voltages. 
TABLE 4

TIME LOST FROM FLASH BURNS

\begin{tabular}{c|c|c|c|c|c}
\hline Nil & $<$ One Week & One Week to One Month & One to Three Months & $>$ Three Months & Total \\
\hline 29 & 5 & 8 & 7 & 5 & 54 \\
\hline
\end{tabular}

It can, therefore, be expected that Joule burns would be caused by medium voltages only if the victim remained in contact with the conductor, whereas a shock of high voltage (likely to be associated with a greater current) might cause burning even if the contact were only brief.

In fact out of 15 cases of Joule burns reported, 14 were associated with "held on" accidents at medium voltage, the other case being associated with an electric shock at 33,000 volts.

As described in Part II of this paper, victims of "held on" accidents were asked to estimate the length of time for which they were held on. On this basis they were divided into three broad groups. But there is no indication that those held on for longer periods were more liable to Joule burn (Table 5). It is possible that whereas the occurrence of Joule burns was not related to the length of time a victim was held on, the severity might have been. The method of investigation in which men were interrogated, in the "additional" cases, several years after the incident, made it impossible to assess the severity of Joule burns, except perhaps by consequent sickness absence. In view of the small number (only 15 cases of Joule burn) it was not feasible to use this method.

Site.-Because a Joule burn results from contact of the body with a conductor this type of accident would be expected to produce injury to the flexor aspect of the fingers or palms and in contrast to flash burns the face would escape. Thirteen Joule burns were on the flexor aspects of the hands or arms and two were on the extensor aspects. One of these burns was on the left thigh and one on the side of the neck.

The case of Joule burning of the side of the neck merits comment.

CASE 69A.-An electrician was standing on a pair of wooden steps holding an earth wire in the left hand whilst stapling it to a beam. He intended to join it to a second wire which was connected to earth. On grasping the second wire with the right hand he received a violent electric shock and was unable to let go (subsequently it proved that the first earth wire which he had been stapling was energized to 240 volts). During the violent shaking which affected him during the shock the energized wire fell across the left side of his neck, where he developed a linear burn. There were no Joule burns on the hands.

It is not easy at first to see why he should develop a burn on the neck and not on the hand. Certainly the skin of the neck is of finer texture than that of the hand and presents a lower resistance to the passage of a current. From the formula ( $\left.I^{2} R t\right)$ quoted earlier, this means that less heat is released. But for a given voltage the current will increase if the resistance is lowered (Ohm's Law), therefore the increased current would cause burning. However, if this were so, the greater current would also pass through the right hand, where the heating effect would be greater than at the neck (for the resistance of the skin of the hand is greater). A possible explanation of the phenomenon is that the area of contact of the conductor at the neck was considerably less than at the right hand and hence the current density (and thus localization of the heating) was greater.

TABLE 6

RELATIONSHIP OF JOULE BURN WITH CURRENT PATHWAY

\begin{tabular}{l|c|c|c}
\hline & Arm to Arm & Arm to Leg & Total \\
\hline Joule burn & 8 & 6 & 14 \\
No Joule burn & 7 & 9 & 16 \\
\hline Total & 15 & 15 & 30 \\
\hline
\end{tabular}

Current Pathway.-In cases of "held on" shock no association was found between the path which the current is presumed to have taken through the body and the incidence of Joule burns (Table 6).

TABLE 5

RELATIONSHIP OF PERIOD “HELD ON" AND JOULE BURN

\begin{tabular}{l|c|c|c|c|c|c}
\hline & Few Seconds & 30 to 60 Seconds & One to Four Minutes & Unknown & Total \\
\hline Joule burn & 7 & 3 & 4 & -2 & 14 \\
\hline
\end{tabular}




\section{Conclusion}

In this series of electrical accidents there were 53 cases of flash burns, 25 cases of shock (including "held on" and not held), and 16 cases of arc eye. There appeared to be no association between voltage and type of injury. The cases of arc eye caused no serious concern. The cases of flash burns varied from trivial singeing of the hairs on the face to more serious burns of hands and face. It seems, as might be expected, that burns from higher voltage flashes are more likely to cause lost time than burns from medium voltage flashes. One case of Joule burn was associated with a high voltage shock, all the others were associated with "held on" type of accidents at medium voltage. In contrast to the flash burns the majority of Joule burns occurred on the flexor surfaces.

Although this series was drawn from persons dealing with high and medium voltages, it is pertinent to note that the medium voltages to which the general population is exposed can be responsible for all the types of hazards encountered.

\section{PART II: ELECTRIC SHOCK}

Part I of this paper describes the method of investigation of a number of victims of electrical accidents and discusses those accidents which did not result in passage of an electric current through the body. This part of the paper considers the cases in which the current did pass through the body. These cases of electric shock are divided into two groups (the "not held" and the "held on") depending on whether or not the victim was held on to the circuit by the current. The three cases of "physical shock" mentioned in the previous paper are also considered.

\section{"Not Held" Shock}

There were 13 cases in this group, of whom 10 were "series cases" and three were "additional cases". They ranged from the severe, to the moderate, when judged by their immediate effects. Two cases in which there was some doubt as to whether or not shock had occurred have been included, but because of the possibility of electric shock they could not be included in the physical shock cases.

The following is an example of the severe type.

Case 13.-A 60-year-old labourer, wearing rubber boots, was standing in a damp trench sawing through a cable believed to be dead. In fact, the cable was energized to 11,000 volts. There was a sudden flash and he became rigid and was thrown backward into the trench; the saw was destroyed. He felt very dazed and although able to climb into the ambulance he did not really recover consciousness until he arrived in hospital a few minutes later. He was detained only a few hours and then sent home. As a result of the accident the backs of his hands were scorched, but not badly enough to require dressing. He was off work only for one day.

As he was wearing rubber boots it is considered more likely that the path of the current was from right hand to left hand (his left hand was holding the earthed armoured covering of the cable) than from hands to feet. He was not wearing gloves.

The moderate type of shock is more familiar.

Case 81.-A 54-year-old female assistant cook was cleaning the top of an electric cooker. She was wearing rubber shoes, she had her left hand on the top of the cooker and a wet cloth in her right hand. She felt a shock up her right arm and the hand contracted breaking the circuit immediately. She was quite well immediately after and lost no time from work. This was presumably a brief arm-to-arm shock.

The two cases in which it was doubtful if a shock had been received are detailed.

Case 25.-A 21-year-old clerk was putting a plug into a metal clad 230 volt socket, in which, apparently, the live wire had become loose and was touching the metal casing. He pressed the switch with his left hand and there was a flash, flame escaping through the chipped plug top. He stated that he felt a slight shock up his left arm. His right arm was not in contact with anything and he was wearing rubber-soled shoes and standing on a wooden floor. If he received a shock it was presumably from the left arm to the feet. This is feasible, for according to Dalziel et al. (1941) the threshold of perception is $1 \mathrm{~mA}$. Applying Ohm's law this allows for a resistance to earth of 230,000 ohms; the resistance of the body could account for anything from 1,000 to 500,000 ohms (Dalziel, 1947) or 800 to 100,000 ohms (Kouwenhoven, 1949), although Emerson (1961) quotes values of 200 to 500 ohms.

Case 32.-A 41-year-old electrician was attending to a domestic immersion heater which was believed to be dead. He grasped two wires with the right hand which were in fact the live and earth conductors. There was a flash and the fuse blew. It is not clear whether the current flowed from one part of his hand to the other or if the two wires touched. There was a very slight burning of the skin, not sufficient to cause blistering. The man was able to carry on with the job and lost no time from work. The question of an electric shock occurring when the two conductors are in contact with the same limb has been mentioned by Kouwenhoven (1949) who reports cases of loss of consciousness from this type of shock even when there has been no burning of the skin.

\section{"Held On" Shock}

There were 30 accidents in which the patient reported that he had been held on to the circuit by the current. The question of Joule burning in these 
circumstances was discussed in the first part of this paper.

Chest and Heart Symptoms.-An interesting feature of the "held on" accidents was the occurrence of chest and heart symptoms, whilst the victim was being held on to the circuit. Ten persons reported chest symptoms such as tightness around the chest, difficulty in breathing, and a sensation of strangulation. Symptoms related to the heart action, such as marked palpitation and a feeling of the heart pounding strongly against the chest wall, were noticed by six persons. Some cases suffered from both chest and heart symptoms.

Joule Burns.- It could be argued that if the skin resistance is lowered as a result of a Joule burn then the consequent increase in current passing through the body would be more likely to produce heart and chest symptoms.

The effect of Joule burning on the resistance of the skin is not simple. Oliver (1913) and François (1955) have stated that there is an increase in resistance, in severe burning. Whereas Kouwenhoven (1949) considers that blistering of the skin in Joule burning leads to a lowered resistance, Lewis (1958) states, "when the skin is burned its resistance is greatly increased; this may break the current. If carbonization takes place resistance of the skin is reduced". It will be seen from Tables 7 and 8 that no association between Joule burning and the reporting of heart and chest symptoms was observed.

Pathway of Current.-Ferris, King, Spence, and Williams (1936) showed that in sheep the minimum current required to produce ventricular fibrillation was $23 \mathrm{~mA}$ when passed from foreleg to hindleg and $136 \mathrm{~mA}$ when passed from foreleg to foreleg. Incidentally, Dalziel (1946) in a critical study of these findings concluded that the minimum fibrillating current for men was about $100 \mathrm{~mA}$. Kouwenhoven, Hooker, and Langworthy (1932) measured, by means of a ring transformer, the proportion of the total current which passed through the heart of experimental animals. They found that $7 \%$ of a current passing from upper extremity to lower extremity went through the heart, whereas if the pathway was from foreleg to foreleg only $3 \%$ passed through the heart. They concluded that "as far as the heart is concerned, fibrillation will be produced by a much smaller total current flowing from the upper to the lower extremities than between the forelegs" and continued, "In most industrial accidents the current flows from the right hand to the feet and thus the heart carries a greater proportion of total current than when contact is made with the circuit at any other locations".
TABLE 7

RELATIONSHIP OF JOULE BURN WITH CHEST SYMPTOMS

\begin{tabular}{l|c|c|c}
\hline & Joule Burn & No Joule Burn & Total \\
\hline Chest symptoms & 4 & 7 & 11 \\
No chest symptoms & 10 & 9 & 19 \\
\hline Total & 14 & 16 & 30 \\
\hline
\end{tabular}

TABLE 8

RELATIONSHIP OF JOULE BURN WITH HEART SYMPTOMS

\begin{tabular}{l|c|c|c}
\hline & Joule Burn & No Joule Burn & Total \\
\hline Heart symptoms & 2 & 4 & 6 \\
No heart symptoms & 12 & 12 & 24 \\
\hline Total & 14 & 16 & 30 \\
\hline
\end{tabular}

TABle 9

RELATIONSHIP OF PATHWAY WITH HEART SYMPTOMS

\begin{tabular}{l|c|c|c}
\hline & Arm to Arm & Arm to Leg & Total \\
\hline Heart symptoms & 2 & 4 & 6 \\
No heart symptoms & 13 & 11 & 24 \\
\hline Total & 15 & 15 & 30 \\
\hline
\end{tabular}

TABLE 10

RELATIONSHIP OF PATHWAY WITH CHEST SYMPTOMS

\begin{tabular}{l|c|c|c}
\hline & Arm to Arm & Arm to Leg & Total \\
\hline Chest symptoms & 5 & 6 & 11 \\
No chest symptoms & 10 & 9 & 19 \\
\hline Total & 15 & 15 & 30 \\
\hline
\end{tabular}

Table 9 shows that in the present series there is no marked association between pathway and heart symptoms.

A similar result is found when the relationship between pathway and chest symptoms is examined (Table 10).

Relationship between Chest Symptoms and Heart Symptoms. - It has been shown by Dalziel et al. (1941) that persons were unable to let go of a conductor carrying a 60 c.p.s. alternating current exceeding 9.7 to $21.6 \mathrm{~mA}$ (all the subjects could release at the lower value, only one at the higher). The difference in frequencies between British 50 c.p.s. and U.S.A. 60 c.p.s. does not materially affect these figures (Dalziel, Ogden, and Abbott, 1943). As noted earlier the threshold for ventricular fibrillation in man is believed to be about $100 \mathrm{~mA}$ and it is to be expected that the current necessary to produce more forceful heart action will be less (by an 
TABLE 11

RELATIONSHIP OF HEART SYMPTOMS WITH CHEST SYMPTOMS

\begin{tabular}{l|c|c|c}
\hline & Chest Symptoms & $\begin{array}{c}\text { No Chest } \\
\text { Symptoms }\end{array}$ & Total \\
\hline Heart symptoms & 4 & 2 & 6 \\
No heart symptoms & 7 & 17 & 24 \\
\hline Total & 11 & 19 & 30 \\
\hline
\end{tabular}

unknown amount). Nevertheless, it might be interesting to see whether persons presented a higher incidence of heart symptoms when subjected to a current which, although great enough to cause chest symptoms, was obviously not sufficient to cause fibrillation. The results are given in Table 11 .

It is seen that out of 11 patients with chest symptoms four had heart symptoms as well, but out of the 19 subjects in which the current was insufficient to cause chest symptoms only two had heart symptoms. These figures only suggest an association between a current strong enough to cause impending asphyxia and the occurrence of heart symptoms. The explanation could lie in increased heart beat caused by the impending asphyxia (Bell, Davidson, and Scarborough, 1956) or a psychological reaction induced by the fear of being held on.

Period of time held on.-It is very difficult for a person, who has undergone the terrifying experience of being held on to an electrical circuit, to estimate accurately the length of time for which he had been held. Nevertheless, all except two men were prepared to estimate this period. It was expressed vaguely and varied from a "few seconds" to "about four minutes". For the purpose of this study it has been decided to make a classification by three periods; "a few seconds", "minutes", and an intermediate group called "30 to 60 seconds". The relationship between period held on and other factors has been studied.

It was noticed in Part I that persons held on for longer periods did not seem any more likely to suffer from Joule burns.

However, chest symptoms were more frequent in persons held on for longer periods, as is seen in Table 12.

Out of 13 persons held on for a few seconds, only two developed chest symptoms whereas of 10 persons held on for minutes, six developed these symptoms.

A similar trend is seen with regard to heart symptoms although the figures are too small to be conclusive (Table 13).

Loss of consciousness. - Of the $\mathbf{3 0}$ men who were "held on", eight reported that they lost consciousness. (Many of these were able to fill in details of the accident from what they had subsequently been told.) It is apparent from Table 14 that those men held on for longer periods are more likely to lose consciousness.

Thus, it will be seen that the longer a victim is held on to an electrical circuit the greater appear to be his chances of developing chest symptoms (indicative of developing asphyxia), possibly heart symptoms, and of losing consciousness. As the estimation of time "held on" is entirely subjective, it could be argued that persons who experienced these phenomena as the result of a shock believe that they have been held on a long time, i.e. their appreciation of the passage of time is disturbed. Whilst this cannot be ruled out, the former hypothesis, that persons held on a longer time are more likely to experience such symptoms, is more feasible.

It is of interest therefore to determine why persons are held on for different periods. The problem can be conveniently studied in two parts:

TABLE 12

RELATIONSHIP OF PERIOD "HELD ON" AND CHEST SYMPTOMS

\begin{tabular}{l|c|c|c|c|c}
\hline & Few Seconds & $30-60$ Seconds & Minutes & Unknown & Total \\
\hline Chest symptoms & 2 & 1 & 6 & 2 & 11 \\
\hline No chest symptoms & 11 & 4 & 4 & - & 19 \\
\hline Total & 13 & 5 & 10 & 2 & 30 \\
\hline
\end{tabular}

TABLE 13

RELATIONSHIP OF PERIOD "HELD ON" AND HEART SYMPTOMS

\begin{tabular}{l|c|c|c|c|c}
\hline & Few Seconds & $30-60$ Seconds & Minutes & Unknown & Total \\
\hline Heart symptoms & 1 & 1 & 2 & 2 & 6 \\
\hline No heart symptoms & 12 & 4 & 8 & -24 \\
\hline Total & 13 & 5 & 10 & 2 & 30 \\
\hline
\end{tabular}


TABLE 14

RELATIONSHIP OF PERIOD "HELD ON" AND LOSS OF CONSCIOUSNESS

\begin{tabular}{l|c|c|c|c|c}
\hline & Few Seconds & $30-60$ Seconds & Minutes & Unknown & Total \\
\hline Consciousness lost & 1 & 1 & 4 & 2 & 8 \\
\hline Consciousness not lost & 12 & 4 & 6 & - & 22 \\
\hline Total & 13 & 5 & 10 & 2 & 30 \\
\hline
\end{tabular}

TABLE 15

METHOD OF RELEASE IN “HELD ON” CASES

\begin{tabular}{|c|c|c|c|c|c|c|c|}
\hline $\begin{array}{l}\text { Case } \\
\text { No. }\end{array}$ & $\stackrel{\mathrm{X}}{\text { Few Seconds }}$ & $\begin{array}{l}\text { Case } \\
\text { No. }\end{array}$ & $\underset{30-60}{\stackrel{Y}{\text { Seconds }}}$ & $\begin{array}{l}\text { Case } \\
\text { No. }\end{array}$ & $\underset{\text { Minutes }}{Z}$ & $\begin{array}{l}\text { Case } \\
\text { No. }\end{array}$ & Unknown \\
\hline $\begin{array}{l}10 \mathrm{~A} \\
11 \mathrm{~A} \\
23 \mathrm{~A} \\
32 \mathrm{~A} \\
32 \mathrm{~B} \\
34 \\
36 \\
48 \\
48 \mathrm{~A} \\
65 \mathrm{~B} \\
69 \mathrm{~A} \\
76 \mathrm{~A}\end{array}$ & $\begin{array}{l}\text { Foreman knocked him off } \\
\text { Moved to position and fell off } \\
\text { Colleague switched off } \\
\text { Threw drill away } \\
\text { Threw himself back, break- } \\
\text { ing contact } \\
\text { Fell off, breaking control } \\
\text { Kicked himself free } \\
\text { Fuses blew } \\
\text { Fuses hlew } \\
\text { Jumped feet off ground (feet } \\
\text { were part of circuit) } \\
\text { Fuse blew } \\
\text { Kicked ladder away and fell } \\
\text { off } \\
\text { Clonic movements of arms } \\
\text { caused him to fall from } \\
\text { perch, breaking contact }\end{array}$ & $\begin{array}{r}39 \\
46 \\
47 \\
42 \\
66 \mathrm{~A} \\
\end{array}$ & $\begin{array}{l}\text { Thinks he fell off after } \\
1 \text { min. } \\
\text { Lost consciousness, } \\
\text { came off (no chest } \\
\text { symptoms) } \\
\text { Suddenly became free } \\
\text { (no chest or heart } \\
\text { symptoms) } \\
\text { Ladder slipped, ? } \\
\text { tetany } \\
\text { Fell off (strangulation, } \\
\text { white haze) }\end{array}$ & $\begin{array}{r}4 A \\
5 \\
16 \\
27 \\
34 A \\
37 \\
40 A \\
51 A \\
67 \\
74\end{array}$ & $\begin{array}{l}\text { Unconscious, fell, pulled } \\
\text { plug out } \\
\text { Release by mate } \\
\text { Mate pulled him off } \\
\text { Foreman pulled him off } \\
\text { A labourer kicked cable } \\
\text { away } \\
\text { Struggled free } \\
\text { Fell off (no chest or } \\
\text { heart symptoms) } \\
\text { Cable burned through } \\
\text { Came off (chest tightness) } \\
\text { Came off (chest tightness) }\end{array}$ & $\begin{array}{l}19 \\
22\end{array}$ & $\begin{array}{l}\text { Pulled off by colleagues } \\
\text { Fell off, jerked off }\end{array}$ \\
\hline
\end{tabular}

(1) How are some victims released from an electrical circuit after being held on for only a few seconds, whilst others are held on for a period of minutes?

(2) How do some persons who have been held on for minutes (and who show a high incidence of impending asphyxia and of unconsciousness) get off, whilst others are known to remain in contact and die?

The second part of the problem might require clarification for it is often stated that a victim becomes unconscious and thereby lets go of the conductor. However, it is well established that isolated muscles can be electrically stimulated, and the intact organism is not needed for this response. It follows, therefore, that the onset of unconsciousness will not necessarily explain release from the circuit. There are three further possible explanations. (i) The onset of a severe degree of anoxia will be accompanied by relaxation of the muscles. This is unlikely because such a severe degree of anoxia would be likely to result in permanent damage to cells of the central nervous system and there was no evidence for this. (ii) Fatigue of the muscles might set in after prolonged strong stimulation. This might take place within a very few minutes (Merton, 1954). (iii) Some central action on the central nervous system may result in generalized loss of muscle tone (as in a faint). This would not affect the muscles under direct stimulation in the pathway of the current but as a result of this loss of tone the centre of gravity of the body might shift, causing the body weight to drag the victim off the conductor.

To study these problems the cases of "held on" shock were divided according to the length of time held on and the method of release noted. This is given briefly in Table 15 .

To answer the first question (release of victims after a few seconds), attention is directed to column $X$. It will be seen that six persons were released by outside help or fortuitous circumstance (Cases 10A, $23 \mathrm{~A}, 48,48 \mathrm{~A}, 69 \mathrm{~A}$, and $83 \mathrm{~A}$ ); of these it is impossible to say how many would have been held on for a longer period and might even have died. Of the remaining seven, all except Case 34 managed to do something to get themselves off the circuit. The answers given by Case 34 were not clear and it was not possible to be sure whether he fell intentionally to break the contact or as part of the accident. But apart from this it is apparent that those who were not released by some external agency were able to adopt some manoeuvre to get off the circuit. This could mean that they had the presence of mind to act before consciousness was impaired or, perhaps more likely, that they were able to adopt such a manoeuvre because they were subjected to a lesser current than the group who were held on longer.

The second question concerns the release of men 
held on for a period estimated at over a minute. From column $Z$ (Table 15) it is seen that five men were released by outside means (Cases 5, 16, 27, $34 \mathrm{~A}$, and 51A). Again it is impossible to state what would have been their fate if some external circumstances had not come to their aid. The remaining five merit individual study.

Case 4A.-This man became unconscious and fell, thereby pulling the electric plug out of a socket. The accident happened more than $\mathbf{3 0}$ years previously and it was not possible to establish whether he lost consciousness from asphyxia or otherwise.

Case 37.-The victim was held by the left arm and managed to struggle free with the right hand which was badly lacerated in the process. He was the only person in the group held on for minutes who freed himself.

Case 40 A.- - He was working at a hole in the road and fell off, fortunately not onto the conductor. He had no symptoms of impending asphyxia (although he had palpitation). He claims not to have lost consciousness. It is difficult to explain this unless one accepts that he had a brief faint.

Case 67 and 74.--Both of these men came off after chest and heart symptoms and were therefore being asphyxiated. Case 67 lost consciousness but 74 states that he did not.

This phenomenon of loss of consciousness resulting in release from a "held on" accident has been recorded also by Cambier (1953).

If it is to be accepted that the two victims who "came off" without losing consciousness (Cases $40 \mathrm{~A}$ and 74), did so because of the onset of muscle fatigue, some residual muscle stiffness would be expected. This was not remarked upon by Case 40A, but Case 74 stated that he had stiffness in the abdominal muscles on the next day, as though he had had unaccustomed exercise. Obviously there is much individual variation because these, or any other possible mechanisms of release, do not operate in all cases; death by asphyxiation is well recognized by forensic pathologists as a cause of death from electric shock. In fact there is now another question: does muscle fatigue set in before death from asphyxia? And if so, why in some cases and not in others?

\section{Physical Shock}

There were three accidents associated with electricity but not causing any electro-pathological phenomena. During work on a live electric conductor there may be a sudden flashover, frequently associated with an explosion. This dramatic happening may not injure the workman and may not be associated with passage of current through the body. As these three accidents have common features they are considered together.
Case 65.-A jointer was using a wooden-handled hacksaw, held in the right hand, to cut through an 11,000 volt cable believed to be dead. He supported the cable with the toe of his left boot. There was a sudden explosion and a flash which vaporized the hacksaw blade. The jointer was quite definite that he did not receive a shock. The current had passed from the core of the cable and along the blade to the earthed armoured casing of the cable. He was thrown out of the pit by the explosion, temporarily blinded by the flash, and was trembling all over and feeling very cold. He was given first-aid treatment (warmth and warm drinks) by his mate and taken to the nearest hospital where he was detained for three hours and then resumed work.

There is little of medical significance in these cases of physical shock, except to note that such symptoms, when encountered after an electric shock, are not necessarily the result of the electric current but may equally well be due to the startling accident itself.

\section{Artificial Respiration}

The currently accepted emergency treatment in cases of electric shock is to apply artificial respiration. In this series only two cases reported that artificial respiration had been applied

Case 19.-A 21-year-old linesman's labourer, working outdoors in hob-nailed boots was standing on wet dewy soil, and grasped a copper wire in contact with a live conductor at 230 volts with the right hand. He could not let go and felt his right arm tightening and then his chest. He stated that he was losing consciousness when rescued and reported that his colleagues said he was going blue. They applied artificial respiration at once and he was taken to the medical unit of a nearby industrial firm (unfortunately the firm kept no record of this incident). He felt "shaky" for half an hour and rested for the remainder of the day although he felt all right. For a week afterwards he felt a stiffness in his neck and chest as though he had had unaccustomed exercise.

Comment.-This man received a "held on" shock from right arm to feet and was apparently being asphyxiated (as indicated by the blue appearance reported and the subsequent muscle stiffness) when he was rescued.

Case 58. -A 31-year-old fitter's mate was working in a sub-station when a three-phase flashover occurred on the 11,000 volt circuit. He received burns to the back of his hands and front of his face, neck, and right wrist (these necessitated a period in hospital of about three or four weeks). The man remembers little of what happened, having only "islands" of memory until about three days after the accident. Artificial respiration was administered at the time of the accident by his colleagues.

Comment.-In this case the victim received artificial respiration although he suffered only from flash burns and did not receive an electric shock. (This finding was confirmed by the safety officer's independent investigation.) 


\section{Treatment}

At the present time the only first-aid treatment for apparent death due to electric shock is artificial respiration. Considerable attention is therefore given to training in the technique of artificial respiration by electricity supply undertakings and firstaid organizations. It is not surprising, therefore, that in the second case quoted above (Case 58) artificial respiration was applied, although it is unlikely that such measures would have been adopted had similar burns been caused by a non-electric source.

Whilst artificial respiration is the only treatment available to first-aiders at the present time, work is proceeding on a simple first-aid method of maintaining the circulation when the heart is not beating, by the application of cardiac massage to the closed chest (Kouwenhoven, Knickerbocker, Milnor, and Jude, 1960) and on a portable defibrillator (Kouwenhoven and Milnor, 1955, 1957; Kouwenhoven, 1960). These developments make it necessary to reassess the place of artificial respiration in electric shock and this study is in progress.

I am grateful to Professor R. E. Lane for his interest and advice during this study. It is a pleasure to thank the chairman of the Electricity Board, in whose area this work was done, the area secretary of the Electrical Trades Union for ready support, and the safety officers for their help and co-operation.

\section{REFERENCES}

Bell, G. H., Davidson, J. N., and Scarborough, H. (1956). Textbook of Physiology and Biochemistry, 3rd ed., p. 467. Livingstone, Edinburgh

Cambier, J. M. (1953). Manifestations Nerveuses des Electrisations Accidentelles. Foulon, Paris.

Dalziel, C. F. (1946). Trans. Amer. Inst. elect. Engrs, 65, 579.

(1947). Elect. Engng (N.Y.), 66, 786

, Lagen, J. B., and Thurston, J. L. (1941). Ibid, 60, 1073.

Ogden, E., and Abbott, C. E. (1943). Ibid, 62, 745.

Emerson, S. J. (1961). Personal communication.

Ferris, L. P., King, B. G., Spence, P. W., and Williams, H. B. (1936), Trans. Amer. Inst. elect. Engrs, $55,498$.

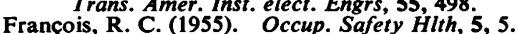
Francois, R. C. (1955). Occup. Safety Hith, 5, 5.
Hughes, J. P. W., and Corney, L. A. (1956). Brit. J. industr. Med., 13,153

Kouwenhoven, W. B. (1949). Elect. Engng (N.Y.), 68, 199. (1960). Personal communication.

, Hooker, D. R., and Langworthy, O. R. (1932). Amer. J. Physiol., 100, 344.

Knickerbocker, G. C., Milnor, W. R., and Jude, J. R. (1960). Elect. Engng $(N, Y)$. 79,500 . and Milnor, W. R. (1955). Ibid, 74, 218.

-, and Milnor, W. R. (1957). $16,220$.

Lew (1957). Ibid, 76, 220 .

Lewis, G. K. (1958). J. Bone Jt Surg., 40A, 27.

Merton, P. A. (1954). J. Physiol. (Lond.), 123, 553.

Minton, J. (1949). Brit. med. J. 1, 392.

Oliver, T. (1913). Lancet, 1, 1575.

Rivers, E. C. (1894). Arch. Ophthal. (N.Y.), 23, 34.

Roy, D. (1897). Amer. J. Ophthal., 14, 353. Tempest, M. N., and Atkins, J. B. (1958). Brit. J. industr. Med.,
15, 147. 